\title{
Post-exercise left ventricular dysfunction measured after a long-duration cycling event
}

\author{
Enrique Serrano Ostariz ${ }^{1}$, Marta López Ramón², Daniel Cremades Arroyos', Silvia Izquierdo Álvarez ${ }^{3^{*}}$, \\ Pilar Catalán Edo ${ }^{1}$, Cristina Baquer Sahún ${ }^{4}$ and Alejandro Legaz Arrese ${ }^{1}$
}

\begin{abstract}
Background: In this research, an extension to our previous work published in the Clinical Journal of Sports Medicine in 2009, we studied subjects that differed in terms of age and training status and assessed the impact of prolonged exercise on systolic and left ventricular diastolic function and cardiac biomarkers levels, recognized as identifiers of cardiac damage and dysfunction. We also assessed the possible influence of event duration, exercise intensity and weight loss (dehydration) on left ventricular diastolic function.

Findings: Ninety-one male cyclists were assessed by echocardiography and serum biomarkers before and after the 2005 Quebrantahuesos cycling event (206 km long and with an accumulated slope of $3800 \mathrm{~m}$ ). Cardiac function was assessed by echocardiography and cardiac biomarkers were assessed in blood serum. Echocardiograms measured left ventricular internal dimension during diastole and systole, left ventricular posterior wall thickness during diastole, interventricular septum thickness during diastole, left ventricular ejection fraction and diastolic filling. The heart rate of 50 cyclists was also monitored during the race to evaluate exercise intensity. Echocardiograph results indicated that left ventricular diastolic and systolic function decreased after the race, with systolic function reduced to a significant degree. Left ventricular ejection fraction was below $55 \%$ in 29 cyclists. The decrease in left ventricular systolic and diastolic function did not correlate with age, training status, race duration, weight loss or exercise intensity.
\end{abstract}

Conclusions: Left ventricular systolic and diastolic function was reduced and cardiac biomarkers were increased after the cycling event, but the mechanisms behind such outcomes remain unclear.

Keywords: Cycling event, Cardiac biomarkers, Prolonged exercise, Strenuous exercise

\section{Findings \\ Background}

This study is a further analysis of data collected for a previous work [1]. One potential effect of prolonged strenuous exercise is exercise-induced cardiac fatigue, described as an alteration to ventricular systolic or diastolic function following such exercise [2,3]. Findings reported for numerous ventricular dysfunction studies have often been inconsistent [3-8], with disparities possibly due to small sample sizes, differences in exercise intensity and duration and great variability in the training

\footnotetext{
* Correspondence: sizquierdo@salud.aragon.es

${ }^{3}$ Servicio de Bioquímica Clínica Planta 3a, Edificio de Consultas Externas, Hospital Universitario Miguel Servet, Calle Padre Arrupe, s/n, Zaragoza 50009, Spain

Full list of author information is available at the end of the article
}

status of the study subjects. As for cardiac-specific biomarkers of damage and dysfunction, a growing number of studies have demonstrated that prolonged and strenuous exercise raises cardiac troponin $\mathrm{T}$ and I (cTnT and cTnI, respectively) and $\mathrm{N}$-terminal pro-brain natriuretic peptide (NT-proBNP) levels [9-14]. The link between systolic and diastolic ventricular dysfunction and the increase in biomarkers is not clear, however [15-18]. Most studies of high-intensity prolonged exercise resulting in increased cardiac biomarkers have been performed in relatively old subjects, but increases are not so evident for elite or professional sportspeople $[19,20]$.

Specific exercise parameters (training status and exercise intensity and duration) that may affect observed changes in biomarkers and ventricular systolic and diastolic function are poorly described and the mechanisms involved are not well understood. To the best of our knowledge,

\section{Biomed Central}

(c) 2013 Serrano Ostariz et al.; licensee BioMed Central Ltd. This is an Open Access article distributed under the terms of the Creative Commons Attribution License (http://creativecommons.org/licenses/by/2.0), which permits unrestricted use, distribution, and reproduction in any medium, provided the original work is properly cited. 
the influence of exercise intensity on left ventricular function has not yet been determined, as we were unable to locate any studies of ventricular dysfunction in cyclists of different ages and training levels for a longduration cycling event (6 hours or more). Therefore, for a long-duration cycling test, we studied, following a similar study [19], the influence of age, level of training, exercise intensity, event duration and weight loss (dehydration) on ventricular function and their association with cardiac biomarkers.

\section{Methods}

\section{Participants and study design}

The study protocol was approved by the Research Ethics Committee of the Government of Aragón (Spain). Amateur male cyclists scheduled to participate in the 2005 Quebrantahuesos Cycle Race (UCI Golden Bike series) were invited to participate in the study via the official race organizer's website [1]. The first 95 volunteers were recruited and their written consent was obtained (note that sample size was limited by the finishing-line resources available). Since 4 cyclists dropped out during the race, the study finally included 91 cyclists, profiled as follows in terms of mean \pm standard deviation (SD): age, $40 \pm 9$ years; height, $1.76 \pm 0.07 \mathrm{~m}$; weight, $74.1 \pm 8.4 \mathrm{~kg}$; and training experience, $12 \pm 7$ years [1]. The race workload (total distance $206 \mathrm{~km}$ for an accumulated slope of $3800 \mathrm{~m}$ ) was comparable to that of the tougher mountain stages of the Tour de France. Ambient temperature during the test ranged between $16^{\circ} \mathrm{C}$ and $32.5^{\circ} \mathrm{C}$.

Subjects completed a general questionnaire, to ascertain personal and cycling history, and a log referring to cycle training in the previous 6 months $(4358 \pm 1731 \mathrm{~km})$. Cyclists were assessed the day before, and approximately 20 minutes after, the cycling event [1]. Cyclists consumed fluid during the event, but, in accordance with guidelines by White et al. [21], consumption was not allowed until after post-race data was collected so as not to influence left ventricular loading.

Pre- and post-race assessment of the 91 cyclists included the following: echocardiography, body mass, heart rate (HR), and blood pressure measurements and a 12-lead electrocardiogram. HR for 50 of the cyclists was also measured during the race using a Polar HR monitor (Polar Team System, Polar Electro Oy, Finland) and the data was downloaded using Polar Precision Performance software (version 3.0) [1]. Maximum HR was calculated using the standard equation $\mathrm{HR}(\max )=$ (220-age). Exercise intensity was defined by the HR ratio as HR (average)/HR ( $\max )$ [22]. Finally, training impulse (TRIMP) values, which are used as an integrative marker of exercise load during competition, were calculated from event duration and the average HR using the formula described by Banister [23].

\section{Echocardiograph procedures}

Participants underwent a resting echocardiographic examination in the left lateral decubitus position. One experienced sonographer performed all the measurements using a commercially available system (ATL ultrasound HDI 5000 ) and a $2.5 \mathrm{MHz}$ phased array transducer. Twodimensionally guided M-mode echocardiograms were obtained from the left parasternal long-axis view. These recordings, made according to American Society of Echocardiography recommendations [24], were used to obtain the following measurements: left ventricular internal dimension during diastole and systole (LVIDd and LVIDs, respectively), left ventricular posterior wall thickness during diastole (LVPWd) and interventricular septum thickness during diastole (IVSDd). Left ventricular ejection fraction (LVEF, \%) was determined by calculating left ventricular volumes according to Teichholz et al. [25]. Doppler echocardiography was used to assess diastolic function. An apical four-chamber view was obtained for a maximized diameter of the mitral annulus. With the sample volume cursor aligned parallel to flow at the mitral annulus level, inflow velocities were interrogated by pulsed-wave Doppler. Minor adjustments were made to the transducer to ensure optimal spectral display, that is, the highest velocity for the least spectral dispersion. The velocity curves were digitized through the darkest grey scale and averages were calculated for the measurements obtained. Peak early and late diastolic filling (E and A, respectively) were measured and the corresponding ratios calculated. HR was determined by limb-lead electrocardiography combined with echocardiography. Blood pressure was simultaneously measured using standard auscultation procedures.

\section{Blood sampling procedures}

Procedures were as described in the previous work published [1]. The upper reference limit (URL) for cTnI (defined as the 99th percentile of healthy participants) was less than $0.04 \mu \mathrm{g} \mathrm{L-1}$ [26]. NT-proBNP levels were measured using an electrochemiluminescence sandwich immunoassay (Elecsys ProBNP, Roche Diagnostics) with the Roche 2010 system. The URL was set at $125 \mathrm{ng} \mathrm{L-1}$ [27]. Haematocrit concentrations were measured using an automated analyser (Sysmex K-1000; Sysmex GmbH, Langenfeld, Germany).

\section{Statistical analyses}

Statistical analyses were performed using SPSS version 14.0. Data were expressed as means and standard deviations. Paired student's t-tests were used to determine differences between pre- and post-race mean values for the various echocardiographic parameters. Analyses for nonGaussian distributed variables were performed using the Wilcoxon test for paired samples. 
Pearson and Spearman correlation coefficients were calculated as standard. Multivariate linear regression was used to assess the relationships between left ventricular diastolic function - measured as the dependent variable - and age, weight loss, training status, event duration and exercise intensity as independent predictors. The level of significance was set to $P<0.05$.

\section{Results}

All 91 cyclists lost weight $(74.2 \pm 8.6 \mathrm{~kg}$ pre-race weight versus $71.8 \pm 8.6 \mathrm{~kg}$ post-race weight; $P<0.001)$ [1] Post-race systolic blood pressure was lower (from $124 \pm$ $12 \mathrm{~mm} \mathrm{Hg}$ to $110 \pm 11 \mathrm{~mm} \mathrm{Hg} P<0.001$ ) [1]. No cyclist required medical attention.

\section{Echocardiographic data}

Baseline echocardiographic examinations revealed no remarkable pathological findings. No cyclist had LVPWd or IVSDd values of more than $12 \mathrm{~mm}$. Mean LVIDd was $51.2 \pm 4.0 \mathrm{~mm}$, mean LVEF (\%) was $67.7 \pm 8.2$ and the mean $\mathrm{E} / \mathrm{A}$ ratio was $1.6 \pm 0.4$.

The cycling event exercise resulted in decreased LVIDd and increased LVIDs in the participants but produced no change in the LVPWd or IVSDd (Table 1). The LVEF (\%) was reduced from $67.7 \pm 8.2$ to $59.7 \pm 9.4$ $(P<0.001)$ and, in 29 cyclists, post-race LVEF was below $55 \%$.

Early transmitral diastolic filling velocities were reduced and late transmitral diastolic filling velocities were increased, resulting in a reduced $\mathrm{E} / \mathrm{A}$ ratio (Table 1 ). The

Table 1 Pre and post-race data (mean \pm standard deviation)

\begin{tabular}{lccc}
\hline & Pre-race & Post-race & $\boldsymbol{P}$ \\
\hline LVIDd (mm) & $51.2 \pm 4.0$ & $47.7 \pm 4.6$ & 0.000 \\
LVIDs (mm) & $29.3 \pm 4.1$ & $30.4 \pm 4.3$ & 0.018 \\
LVPWd (mm) & $9.6 \pm 1.1$ & $9.6 \pm 0.9$ & 0.80 \\
IVSDd (mm) & $9.6 \pm 1.1$ & $9.5 \pm 1.0$ & 0.58 \\
LVEF (\%) & $67.7 \pm 8.2$ & $59.7 \pm 9.4$ & 0.000 \\
E/A & $1.6 \pm 0.4$ & $1.1 \pm 0.3$ & 0.000 \\
CTnl ( $\mu$ g L-1) & $0.006 \pm 0.015$ & $0.056 \pm 0.059$ & 0.000 \\
NT-proBNP (ng L-1) & $27 \pm 16$ & $189 \pm 111$ & 0.000 \\
HR (per min) & $58 \pm 8$ & $86 \pm 11$ & 0.000 \\
BPS (mmHg) & $125 \pm 12$ & $110 \pm 12$ & 0.000 \\
BPD (mmHg) & $65 \pm 10$ & $62 \pm 111$ & 0.049 \\
Ht (\%) & $43.3 \pm 2.1$ & $44.6 \pm 2.9$ & 0.000 \\
Weight (kg) & $74.3 \pm 8.4$ & $72.0 \pm 8.5$ & 0.000 \\
\hline Abbrevatons BPD dastic & &
\end{tabular}

Abbreviations: BPD diastolic blood pressure, BPS systolic blood pressure, $C T n I$ cardiac troponin I, E/A ratio of early to late peak diastolic transmitral flow velocities, $H R$ heart rate, $H t$ haematocrit, IVSDd interventricular septum thickness during diastole, LVEF left ventricular ejection fraction, LVIDd left ventricular internal dimension during diastole, LVIDs left ventricular internal dimension during systole, LVPWd left ventricular posterior wall thickness during diastole, NT-proBNP N-terminal pro-brain natriuretic peptide. post-race increase in HR was not significantly associated with alterations in the LVEF and the E/A ratio. The LVIDd was not related to any of the observed functional changes. Overall, there were no significant associations between alterations in cardiac function (systolic or diastolic) and age, training status, event duration, weight loss, exercise intensity (the HR (average)/HR ( $\max )$ ratio or TRIMP values) and NT-proBNP. When we considered multivariate regression, the model was not significant (systolic: $\mathrm{R}^{2}=$ 0.147, $P=0.267$; diastolic: $\mathrm{R}^{2}=0.091, P=0.599$ ).

\section{Biochemical markers}

Post-race cTnI and NT-proBNP levels were significantly raised, with $43 \%$ of participants exhibiting cTnI levels above $0.04 \mu \mathrm{g} \mathrm{L}-1$ and with $65 \%$ of the participants exhibiting NT-proBNP levels above $125 \mathrm{ng}$ L-1 [1]. The increases, however, did not correlate with post-race cardiac function.

\section{Discussion}

The results of this study confirm those of previous studies (running and ironman) in demonstrating that prolonged strenuous exercise reduces systolic and diastolic function [6,21,28-30] and increases the cardiac-specific markers cTnI and NT-proBNP [5,10,13,14,30,31].

The decrease in post-race LVEF supports the suggestion that systolic changes only develop during longduration events $[5,12,15,21,32,33]$.

No previous studies have been conducted for amateur cyclists of different ages and training levels or for longduration cycling events (more than 6 hours). The long duration of the event may explain the deterioration in ventricular function in most cyclists in our study, as this finding coincides with the deterioration reported in studies for other longer duration tests.

The decrease in LVEF in the presence of decreased systolic blood pressure reflects depressed cardiac contractility. The lack of correlation between weight changes, LVIDd and diastolic function measurements suggests that the depression in diastolic function represents a true reduction in left ventricular function. Furthermore, although post-race HR increased significantly compared to pre-race $\mathrm{HR}$, the absence of any significant correlation between HR and any Doppler-derived index of diastolic function supports the presence of a change in diastolic function.

Although our results agree with previously reported results, they should be interpreted with care. We report a weight loss of over $3 \%$, which can be interpreted as a high degree of dehydration. We used weight changes and LVIDd as cardiac preload indicators; using weight loss as a preload indicator is open to question, however, as preload may be maintained by internal fluid shifts from the extravascular to intravascular space [29]. 
Moreover, although LVIDd may have been used as a measure of left ventricular preload in some studies $[6,30,34]$, it is important to note that this parameter has limited use as a preload surrogate, given that the internal diameter of the left ventricle is inherent to the calculation of the LVEF.

Although our study has limitations because the parameters used to measure diastolic function are loaddependent, our findings agree with other studies that reported a reduction in diastolic function using a less load-dependent measure of diastolic function (tissue Doppler imaging and 2D strain analysis). Changes in diastolic function following exercise were unrelated to changes in preload-related indexes (LVIDd and haematocrit) and HR. Even in a controlled laboratory environment, where fluid ingestion was monitored throughout exercise and loading conditions were restored during the postexercise assessment period, a decline in left ventricular diastolic function was observed. This suggests that the alterations in left ventricular relaxation are probably related to other underlying mechanisms [35].

Hence, as per Shave et al. [6], investigators may wish to use tissue Doppler imaging or 2D strain analysis to gain a better understanding of global left ventricular function after prolonged exercise, independently of left ventricular loading conditions.

The significant increase in highly specific cardiac injury biomarkers like cTnI and NT-proBNP observed in this study indicates that myocardial damage may have occurred as a result of prolonged strenuous exercise [1]. Damage to myocardial cells may cause the changes in cardiac function reported in several studies [21,22,36,37]. Nevertheless, it is not clear whether the changes in function or the release of biomarkers represent dysfunction or represent damage [37]. Moreover, according to most previous studies $[6,28,37,38]$, the release of biomarkers and the changes in left ventricular function observed after prolonged strenuous exercise may be two concomitant, yet independent, phenomena.

\section{Conclusions}

A long-duration cycling event led to a reduction in left ventricular systolic and diastolic function in cyclists and the unrelated appearance of elevated serum markers of cardiac myocardial cell damage. Nonetheless, the mechanisms behind these outcomes remain unknown. It is likely that factors other than myocardial damage contributed to the decrease in left ventricular function after intense exercise.

\section{Abbreviations}

cTnl: Cardiac troponin I; IVSDd: Interventricular septum thickness during diastole; LVEF: Left ventricular ejection fraction; LVIDd: Left ventricular internal dimension during diastole; LVIDs: Left ventricular internal dimension during systole; LVPWd: Left ventricular posterior wall thickness during diastole; NT-proBNP: N-terminal proBNP.

\section{Competing interests}

The authors declare that they have no competing interests.

\section{Authors' contributions}

ESO conceived the study, participated in its design and coordination and helped draft the manuscript. MLR carried out tests, participated in designing the study and performed the statistical analysis. DCA carried out tests and assays and participated in designing the study. SIA helped draft the manuscript, revised it critically for intellectual content and gave final approval of the version to be published. PCE carried out the assays and participated in designing the study. CB and ALA participated in the sequence alignment and helped draft the manuscript. All authors read and approved the final manuscript.

\section{Acknowledgements}

Grateful thanks to participants in this study. Ailish M J Maher revised the English in a version of the manuscript.

\section{Author details}

${ }^{1}$ Physical Education and Sports Section, Universidad de Zaragoza, Zaragoza, Spain. ${ }^{2}$ Cardiology Service, Hospital Universitario Miguel Servet, Zaragoza, Spain. ${ }^{3}$ Servicio de Bioquímica Clínica Planta 3a, Edificio de Consultas Externas, Hospital Universitario Miguel Servet, Calle Padre Arrupe, s/n, Zaragoza 50009, Spain. ${ }^{4}$ Hospital Clínico Universitario Lozano Blesa, Zaragoza, Spain.

Received: 26 November 2012 Accepted: 21 May 2013

Published: 26 May 2013

\section{References}

1. Serrano E, Legaz A, Terreros JL, López M, Cremades D, Carranza LE, Izquierdo S, Bocos P: Cardiac biomarkers and exercise duration and intensity during a cycle-touring event. Clin J Sport Med 2009, 19:293-299.

2. Douglas PS, OToole ML, Hiller WD, Hackney K, Reichek N: Cardiac fatigue after prolonged exercise. Circulation 1987, 76:1206-1213.

3. Oxborough D, Birch K, Shave R, George K: "Exercise-induced cardiac fatigue"-a review of the echocardiographic literature. Echocardiography 2010, 27:1130-1140.

4. Lucia A, Serratosa L, Saborido A, Pardo J, Boraita A, Morán M, Bandrés F, Megías A, Chicharro JL: Short-term effects of marathon running: No evidence of cardiac dysfunction. Med Sci Sports Exerc 1999, 31:1414-1421.

5. Shave R, Dawson E, Whyte G, George K, Gaze D, Collinson P: Altered cardiac function and minimal cardiac damage during prolonged exercise. Med Sci Sports Exerc 2004, 36:1098-1103.

6. Whyte G, George K, Shave R, Dawson E, Stephenson C, Edwards B, Gaze D, Oxborough D, Forster J, Simspon R: Impact of marathon running on cardiac structure and function in recreational runners. Clin Sci (Lond) 2005, 108:73-80.

7. Hassan MY, Noakes TD, Berlyn P, Shave R, George K: Preload maintenance protects against a depression in left ventricular systolic, but not diastolic, function immediately after ultraendurance exercise. Br J Sport Med 2006, 40:536-540.

8. Middeleton N, Shave R, George K, Whyte G, Hart E, Atkinson G: Left ventricular function immediately following prolonged exercise: A metaanalysis. Med Sci Sports Exerc 2006, 38:681-687.

9. Herrmann M, Scharhag J, Miclea M, Urhausen A, Herrmann W, Kindermann W: Post-race kinetics of cardiac troponin T and I and Nterminal pro-brain natriuretic peptide in marathon runners. Clin Chem 2003, 49:831-834.

10. Vidotto C, Tschan H, Atamaniuk J, Pokan R, Bachl N, Müller MM: Responses of N-terminal pro-brain natriuretic peptide (NT-proBNP) and cardiac troponin I (cTnl) to competitive endurance exercise in recreational athletes. Int J Sports Med 2005, 26:645-650.

11. Shave R, George KP, Atkinson G, Hart E, Middleton N, Whyte G, Gaze D, Collinson PO: Exercise-induced cardiac troponin T release: a metaanalysis. Med Sci Sports Exerc 2007, 39:2099-2106.

12. La Gerche A, Connelly KA, Mooney DJ, Macisaac Al, Prior DL: Biochemical and functional abnormalities of left and right ventricular function after ultra-endurance exercise. Heart 2008, 94:860-866. 
13. Serrano-Ostáriz E, Terreros-Blanco JL, Legaz-Arrese A, George K, Shave R, Bocos-Terraz P, Izquierdo-Álvarez S, Bancalero JL, Echavarri JM, Quilez J, Aragonés MT, Carranza-García LE: The impact of exercise duration and intensity on the release of cardiac biomarkers. Scand J Med Sci Sports 2011, 2:244-249

14. Legaz-Arrese A, George K, Carranza-García LE, Munguía-Izquierdo D, MorosGarcía T, Serrano-Ostáriz E: The impact of exercise intensity on the release of cardiac biomarkers in marathon runners. Eur J Appl Physiol 2011, 111:2961-2967.

15. Rifai N, Douglas PS, O'Toole M, Rimm E, Ginsburg GS: Cardiac troponin T and $\mathrm{I}$, echocardiographic wall motion analyses, and ejection fractions in athletes participating in the Hawaii Ironman Triathlon. Am J Cardiol 1999, 83:1085-1089.

16. Neilan TG, Januzzi JL, Lee-Lewandrowski E, Ton-Nu T, Yoerger DM, Jassal DS, Lewandrowski KB, Siegel AJ, Marshall JE, Douglas PS, Lawlor D, Picard $\mathrm{MH}$, Wood MJ: Myocardial injury and ventricular dysfunction related to training levels among nonelite participants in the Boston Marathon. Circulation 2006, 114:2325-2333.

17. Wilson M, O'Hanlon R, Prasad S, Oxborough D, Godfrey R, Alpendurada F, Smith G, Wong J, Basavarajaiah S, Shama S, Nevill A, Gaze D, George K, Whyte G: Biological markers of cardiac damage are not related to measures of cardiac systolic and diastolic function using cardiovascular magnetic resonance and echocardiography after an acute bout of prolonged endurance exercise. Br J Sports Med 2011, 45:780-784.

18. Mousavi N, Czarnecki N, Kumar K, Fallah-Rad N, Lytwyn M, Han SY, Francis A, Walker JR, Kirkpatrick ID, Neilan TG, Sharma S, Jassal DS: Relation of biomarkers and cardiac magnetic resonance imaging after marathon running. Am J Cardiol 2009, 103:1467-1472.

19. König D, Schumacher $Y O$, Heinrich L, Schmid A, Berg A, Dickhuth $\mathrm{HH}$ : Myocardial stress after competitive exercise in professional road cyclists. Med Sci Sports Exerc 2003, 35:1679-1683.

20. Carranza LE, George K, Serrano E, Casado R, Caballero AL, Legaz A: Cardiac biomarker response to intermittent exercise bouts. Int J Sports Med 2011 32:327-331.

21. Whyte GP, George K, Sharma S, Lumley S, Gates P, Prasad K, McKenna WJ: Cardiac fatigue following prolonged endurance exercise of differing distances. Med Sci Sports Exerc 2000, 32:1067-1072.

22. Neumayr G, Pfister R, Mitterbauer G, Gaenzer H, Sturm W, Eibl G, Hoertnagl $\mathrm{H}$ : Exercise intensity of cycle-touring events. Int J Sports Med 2002, 23:505-509.

23. Banister EW: Modeling elite athletic performance. In Physiological Testing of Elite Athletes. Edited by Green HJ, McDougal JD, Wenger H. Champaign: Human Kinetics; 1991:403-424.

24. Sahn DJ, DeMaria A, Kisslo J, Weyman A: Recommendations regarding quantitation in M-mode echocardiography: results of a survey of echocardiographic measurements. Circulation 1978, 58:1072-1083.

25. Teicholz LE, Kreulen T, Herman MV, Gorlin R: Problems in echocardiographic volume determinations: echocardiographicangiographic correlations in the presence or absence of asynergy. Am J Cardiol 1976, 37:7-11.

26. Apple FS, Quist HE, Doyle PJ, Otto AP, Murakami MM: Plasma $99^{\text {th }}$ percentile reference limits for cardiac troponin and creatine kinase MB mass for use with European Society of Cardiology/American College of Cardiology consensus recommendations. Clin Chem 2003, 49:1331-1336.

27. Al-Barjas M, Nair D, Ayrton P, Morris R, Davar J: How can the role of $\mathrm{N}$ terminal pro B Natriuretic Peptide (NT-proBNP) be optimised in heart failure screening? A prospective observational comparative study. Eur Heart J Fail 2004, 3(Suppl. 1):51.

28. Shave RE, Dawson E, Whyte G, George K, Ball D, Gaze DC, Collinson PO: Evidence of exercise-induced cardiac dysfunction and elevated cTnT in separate cohorts competing in an ultra-endurance mountain marathon race. Int J Sports Med 2002, 23:489-494.

29. Oxborough D, Shave R, Middleton N, Whyte G, Forster J, George K: The impact of marathon running upon ventricular function as assessed by 2D, Doppler, and tissue-Doppler echocardiography. Echocardiography 2006, 23:635-641.

30. Middleton N, Shave R, George K, Whyte G, Simpson R, Florida-James G, Gaze D: Impact of repeated prolonged exercise bouts on cardiac function and biomarkers. Med Sci Sports Exerc 2007, 39:83-90.
31. Koller A, Sumann G, Griesmacher A, Falkensammer G, Klingler A, Fliri G, Greie S, Schobersberger W: Cardiac troponins after a downhill marathon. Int J Cardiol 2008, 129:449-452.

32. Tulloh L, Robinson D, Patel A, Ware A, Prendergast C, Sullivan D, Pressley L: Raised troponin $\mathrm{T}$ and echocardiographic abnormalities after prolonged strenuous exercise-the Australian Ironman Triathlon. Br J Sports Med 2006, 40:605-609.

33. Ketelhut R, Losem CJ, Messerli FH: Is a decrease in arterial pressure during longterm aerobic exercise caused by a fall in cardiac pump function? Am Heart J 1994, 127:567-571.

34. Percy RF, Conetta DA, Miller AB: Echocardiographic assessment of the left ventricle of endurance athletes just before and after exercise. Am J Cardio/ 1990, 65:1140-1144.

35. Banks L, Sasson Z, Busato M, Goodman JM: Impaired left and right ventricular function following prolonged exercise in young athletes: influence of exercise intensity and responses to dobutamine stress. J Appl Physiol 2010, 108:112-119.

36. George K, Whyte G, Stephenson C, Shave R, Dawson E, Edwards B, Gaze D, Collinson P: Postexercise left ventricular function and CTnT in recreational marathon runners. Med Sci Sports Exerc 2004, 36:1709-1715.

37. Siegel AJ, Lewandrowski EL, Chun KY, Sholar MB, Fischman AJ, Lewandrowski KB: Changes in cardiac markers including B-natriuretic peptide in runners after the Boston marathon. Am J Cardiol 2001, 88:920-923.

38. Scharhag J, Urhausen A, Schneider G, Herrmann M, Schumacher K, Haschke M, Krieg A, Meyer T, Herrmann W, Kindermann W: Reproducibility and clinical significance of exercise-induced increases in cardiac troponins and $\mathrm{N}$-terminal pro brain natriuretic peptide in endurance athletes. Eur J Cardiovasc Prev Rehabil 2006, 13:388-397.

doi:10.1186/1756-0500-6-211

Cite this article as: Serrano Ostariz et al:: Post-exercise left ventricular dysfunction measured after a long-duration cycling event. BMC Research Notes 2013 6:211.

\section{Submit your next manuscript to BioMed Central and take full advantage of:}

- Convenient online submission

- Thorough peer review

- No space constraints or color figure charges

- Immediate publication on acceptance

- Inclusion in PubMed, CAS, Scopus and Google Scholar

- Research which is freely available for redistribution 